\title{
Determination of key parameters (air exchange rate, penetration factor and deposition rate) for selecting residential air cleaners under different window airtightness levels
}

\begin{abstract}
Healthy indoor air quality is a basic standard for good living environment, and air cleaners are commonly used in residential applications, especially in China, to control indoor $\mathrm{PM}_{2.5}$ pollutions from outdoors. An accurate cleaner selection method will help keep satisfying indoor air quality, as well as reducing cost and materials of equipment. Three key parameters, namely, air exchange rate $(a)$, particle penetration factor $(P)$ and deposition rate $(k)$, have been suggested as direct influence on air cleaner selection when pollutants are coming from building infiltration. In relevant standards, however, there is no method that can link the three key parameters to various airtightness levels of external windows, which may often exist in real applications. This study, therefore, has proposed a calculation method for deciding $a, P$ and $k$, based on monitored indoor and outdoor $\mathrm{PM}_{2.5}$ mass concentrations, with given recommended design values under different external window airtightness levels. Results showed that both air exchange rates and penetration factors were significantly influenced by the airtightness level of windows, and both their values were found to be different from the recommended values in the current Chinese standard, providing evidence to support future standard revision and update. Meanwhile, deposition rates showed good agreement with the recommended value in the current Chinese standard (i.e. $0.2 \mathrm{~h}^{-1}$ ). Additionally, with increased window airtightness level, the required clean air delivery rate (CADR) of air cleaners showed a downward trend, which means an air cleaner with smaller size, lower energy consumption and less material.
\end{abstract}

Key words: Fine particulate matter $\left(\mathrm{PM}_{2.5}\right)$ pollution; Air cleaner; Air exchange rate; Penetration factor; Deposition rate; Window airtightness level 


\section{Introduction}

In current society, people are spending over $90 \%$ time inside buildings. Therefore, providing a healthy indoor air quality is essential for developing livable and sustainable buildings (Martins and Carrilho da Graça, 2018; Salonen et al., 2013; Sharmin et al., 2014). In the past few decades, China has experienced a rapid development in economy and urbanization. However, the issue of atmosphere pollution has also become serious, and the impact of fine particulate matter $\left(\mathrm{PM}_{2.5}\right)$ on people's health conditions has captured great attention of researchers (Chan and Yao, 2008; Chatzidiakou et al., 2012; Kong et al., 2020; Roelofsen, 2018). PM$_{2.5}$ refers to those airborne particulate matters with aerodynamic diameters smaller than $2.5 \mu \mathrm{m}$, which is inhalable by human to affect their health (Fang et al., 2020; Pateraki et al., 2020; Velasco and Rastan, 2015).

Under serious outdoor $\mathrm{PM}_{2.5}$ pollution conditions, people usually choose to close all external windows to prevent outdoor $\mathrm{PM}_{2.5}$ going into indoors. However, much evidence has proven that outdoor $\mathrm{PM}_{2.5}$ can still penetrate into indoors by infiltration through existing cracks on building facades, especially around windows (Liu et al., 2019; Stapleton and Ruiz-Rudolph, 2018; Tran et al., 2017). To obtain healthy indoor air quality, air cleaners are being widely used in China to tackle high level of $\mathrm{PM}_{2.5}$ pollution outdoors (Deng et al., 2017; Liu et al., 2017; Zhang et al., 2011; Zhao et al., 2016). Existing studies have revealed that when all external windows are closed, the removal capacity of air cleaners to $\mathrm{PM}_{2.5}$ is greatly influenced by its clean air delivery rate (CADR), room dimensions (such as the height and area), room air exchange rate $(a)$, kinetic characteristics of $\mathrm{PM}_{2.5}$ (penetration factor $(P)$ and deposition rate $(k)$ ) and outdoor $\mathrm{PM}_{2.5}$ pollution level (Jin et al., 2016; Shaughnessy and Sextro, 2006; Xu, 2019). Namely, all these parameters are needed when selecting appropriate air cleaners for specific applications.

To guide design and selection of air cleaners, the American Household Appliance Manufacturers Association (AHAM) has proposed a standard, namely, ANSI/AHAM $A C-1-2006$. In this standard, the relationship between air cleaners' effective area and CADR has been established, with other parameters described as influential factors. In this relationship, the room height is dependent on the building under investigation and the outdoor $\mathrm{PM}_{2.5}$ mass concentration is mainly determined by local atmospheric pollution level. The remaining three parameters, i.e. $P, k$ and $a$, were often set as constant values for all buildings. For example, under natural ventilation conditions, 
$a=1.0 \mathrm{~h}^{-1}, P=1.0$ and $k=0.2 \mathrm{~h}^{-1}$, which were recommended by ANSI/AHAM AC-1-2006. The Chinese standard, GB/T 18801-2015, was developed in 2015, according to the American standard ANSI/AHAM AC-1-2006. For buildings in China (mostly under infiltration condition), the three parameters were recommended as $a=0.6 \mathrm{~h}^{-1}, P=0.8$ and $k=0.2 \mathrm{~h}^{-1}$. This method of using constant values for these three parameters has been adopted by standards of other countries as well, such as Canada (NRCC-54013) and Japan (JEM 1467-2013).

In real buildings, however, most of these parameters were influenced significantly by the airtightness level of external windows (Lai, 2003; Provan and Younger, 1986; Wallace, 1996; Younes et al., 2012). For $a$, many studies have justified that it is indirectly proportion to the airtightness level of windows (Carrilho et al., 2015; Cui et al., 2015; Deng et al., 2018; Kiwan et al., 2013; Montoya et al., 2011; Younes et al., 2012), as well as $P$ (Chen et al., 2012; Li and Chen, 2003; Tian et al., 2009). For $k$, however, sufficient evidence is available showing that there is no significant impact from airtightness level of windows (El Hamdani et al., 2008; Lai, 2003; Zhao and Wu, 2007). Therefore, it seems to be reasonable to use a constant value defined in the standard for $k$ when selecting air cleaners. However, if the same method is also used for $a$ and $P$, the selected air cleaner may not be appropriate for buildings with different airtightness levels of external windows.

To quantifiable identify the impact of this assumption, this paper has introduced a study calculated $P, a$, as well as $k$ (to decide a practical constant value for $k$ ) by indoor and outdoor $\mathrm{PM}_{2.5}$ mass concentrations, under different airtightness levels of external windows. In the study, both indoor and outdoor $\mathrm{PM}_{2.5}$ mass concentrations from five rooms with different airtightness levels of external windows have been monitored for calculation. Based on the quantified impact, recommended values were provided to guide selection of air cleaners more specifically to the application.

\section{Model Development}

\subsection{Model deduction}

Many studies have revealed that even when all external windows are closed and all fresh air ventilation systems are off, outdoor $\mathrm{PM}_{2.5}$ can still enter indoors through cracks around external windows, by infiltration (Liu et al., 2019; Stapleton and Ruiz- 
Rudolph, 2018; Tran et al., 2017). Under this circumstance, indoor $\mathrm{PM}_{2.5}$ is mainly coming from outdoors and the level is dependent on the rate/amount of outdoor $\mathrm{PM}_{2.5}$ going into indoors, Equation 1 set up a dynamic equilibrium equation between indoor and outdoor $\mathrm{PM}_{2.5}$ mass concentrations (Chen and Zhao, 2011),

$$
\frac{\mathrm{d} C_{i n}}{\mathrm{~d} t}=a P C_{o u t, t}-a C_{i n, t}-k C_{i n, t}
$$

where $C_{\text {in }}, C_{\text {out }}$ are indoor and outdoor $\mathrm{PM}_{2.5}$ mass concentrations, respectively, (in $\mu \mathrm{g} / \mathrm{m}^{3}$ ); $a$ is air exchange rate, (in $\mathrm{h}^{-1}$ ); $P$ and $k$ are $\mathrm{PM}_{2.5}$ penetration factor and deposition rate, respectively (in dimensionless and $\mathrm{h}^{-1}$ ).

Both Bennett and Koutrakis (2006) and Mleczkowska et al. (2016) have suggested that for a given building structure, Equation 1 can be solved by discreet time steps, expressed as Equation 2,

$$
C_{i n, t}=\frac{a_{i} P C_{\text {out } t-\Delta t}}{\left(k+a_{i}\right)}\left(1-e^{-\left(k+a_{i}\right) \Delta t}\right)+C_{i n, t-\Delta t} \cdot e^{-\left(k+a_{i}\right) \Delta t}
$$

where $\Delta t$ is time step, (in h).

Equation 2 can then be transferred into Equations 3 for different time steps.

$$
\left\{\begin{aligned}
C_{i n, 2}= & \frac{a_{1} P C_{\text {out }, 1}}{\left(k+a_{1}\right)}\left(1-e^{-\left(k+a_{1}\right)}\right)+C_{i n, 1} \cdot e^{-\left(k+a_{1}\right)} \\
C_{i n, 3}= & \frac{a_{2} P C_{\text {out }, 2}}{\left(k+a_{2}\right)}\left(1-e^{-\left(k+a_{2}\right)}\right)+C_{i n, 2} \cdot e^{-\left(k+a_{2}\right)} \\
& \ldots \\
C_{i n, i}= & \frac{a_{i-1} P C_{\text {out }, i-1}}{\left(k+a_{i-1}\right)}\left(1-e^{-\left(k+a_{i-1}\right)}\right)+C_{i n, i-1} \cdot e^{-\left(k+a_{i-1}\right)} \\
& \ldots \\
C_{i n, n}= & \frac{a_{n-1} P C_{\text {out }, n-1}}{\left(k+a_{n-1}\right)}\left(1-e^{-\left(k+a_{n-1}\right)}\right)+C_{i n, n-1} \cdot e^{-\left(k+a_{n-1}\right)}
\end{aligned}\right.
$$

\subsection{Model solutions}

In Equation 3, when both indoor and outdoor $\mathrm{PM}_{2.5}$ mass concentrations for the period of $n$ hours are known, it has $n-1$ equations and $n+1$ unknowns ( $a_{1} \sim a_{n-1}, P$ and $k$ ), 
with larger number of unknowns than knowns. For $P$, previous studies have revealed that for traditional building structure its value is mostly ranging from 0.8 to 1.0 , and for a given building it is almost a constant (Chen et al., 2012; Tian et al., 2009). For $k$, it mainly ranges between 0 and $0.4 \mathrm{~h}^{-1}$, and can be considered as constant for unoccupied rooms with certain structure under infiltration only (no active natural and mechanical ventilation systems) (Bennett and Koutrakis, 2006; Mleczkowska et al., 2016).

To solve Equation 3, therefore, the above two ranges for $P$ and $k$, have been used. During the solving process, both values were selected at every 0.01 change within the range, i.e. $P_{m}=0.80,0.81, \ldots, 0.99,1.00 ; k_{j}=0.01,0.02, \ldots, 0.39,0.40$, in $^{-1}$, following the method adopted by Bennett and Koutrakis (2006). Therefore, the combination between $P_{m}$ and $k_{j}$, referred as $\left[P_{m}, k_{j}\right]$, could be established and expressed in Equation 4 , with a total number of $\left[P_{m}, k_{j}\right]$ as 840 (i.e. $21 \times 40$ ). Then, substituting one combination of $\left[P_{m}, k_{j}\right]$ together with corresponding field measured indoor and outdoor $\mathrm{PM}_{2.5}$ mass concentrations in $n$ hours into Equation 3 gives a group of $a\left(\left[a_{m, j}^{1}, a_{m, j}^{2}, \ldots, a_{m, j}^{n-1}\right]\right)$. Using the same method, all 840 groups of $a$ (with corresponding $\left[P_{m}, k_{j}\right]$ ) can be calculated.

$$
\left[P_{m}, k_{j}\right]=\left[\begin{array}{cccccc}
(0.80,0.01) & (0.80,0.02) & \ldots & \left(0.80, k_{i}\right) & \ldots & (0.80,0.4) \\
(0.81,0.01) & (0.81,0.02) & \ldots & \left(0.81, k_{i}\right) & \ldots & (0.81,0.4) \\
\ldots & \ldots & \ldots & \ldots & \ldots & \ldots \\
\left(P_{m}, 0.01\right) & \left(P_{m}, 0.02\right) & \ldots & \left(P_{m}, k_{i}\right) & \ldots & \left(P_{m}, 0.4\right) \\
\ldots & \ldots & \ldots & \ldots & \ldots & \ldots \\
(1,0.01) & (1,0.02) & \ldots & \left(1, k_{i}\right) & \ldots & (1,0.4)
\end{array}\right]
$$

The determination of reasonable solutions for all 840 groups of $a$ (with corresponding $\left.\left[P_{m}, k_{j}\right]\right)$ was based on two basic principles/methods:

1) the value of $a$ should be within the range of 0 and $1.0 \mathrm{~h}^{-1}$, according to Montoya et al. (2011); Shi et al. (2015); Yamamoto et al. (2010);

2) $a$ was selected by its standard deviation $\delta_{m, j}$ (as calculated by Equation 5) and the ones with lowest $5 \%$ were selected, together with corresponding $\left[P_{m}, k_{j}\right]$, and hourly mean values of all reasonable solutions $\left(\left[\overline{a_{m, j}^{1}}, \overline{a_{m, j}^{2}}, \ldots, \overline{a_{m, j}^{5}}\right]\right.$ and $\left.\left[\overline{P_{m}}, \overline{k_{j}}\right]\right)$ are considered as the solutions of Equation 3, according to Bennett and Koutrakis (2006); Mleczkowska et al. (2016);

$$
\delta_{m, j}=\sqrt{\frac{1}{n-1} \sum_{i=1}^{n-1}\left(a_{m, j}^{i}-u\right)^{2}}
$$

where $u$ is the arithmetic mean value of corresponding $\left[a_{m, j}^{1}, a_{m, j}^{2}, \ldots, a_{m, j}^{n-1}\right]$. 
In the proposed method above, both indoor-outdoor $\mathrm{PM}_{2.5}$ mass concentrations and outdoor meteorological parameters can be considered as potential uncertainties in the modelling work, especially due to their stochastic nature. Their impact on the modelling accuracy has been considered in this study and appropriate discussions and justifications are available in Section 3.2.

\section{Data Collection and Model Validation}

\subsection{Data collection}

To validate the model solved in Section 2.2, field data were collected from five unoccupied offices located in Beijing, China. Measured parameters included outdoor and indoor $\mathrm{PM}_{2.5}$ mass concentrations, outdoor temperature, wind speed and relative humidity.

\subsubsection{Sampling sites and monitoring equipment}

Figure 1 depicts the locations of all five monitored offices in this study, numbered from Sampling Site 1 (SS1) to Sampling Site 5 (SS5), and all five sampling sites are located in the central area of Beijing, China. Among them, SS1 is located in northern Beijing and SS2-SS5 are located southeastern Beijing. All are within 6km radius to the central Beijing. Table 1 has listed some basic information about all these rooms (Chen et al., 2016).

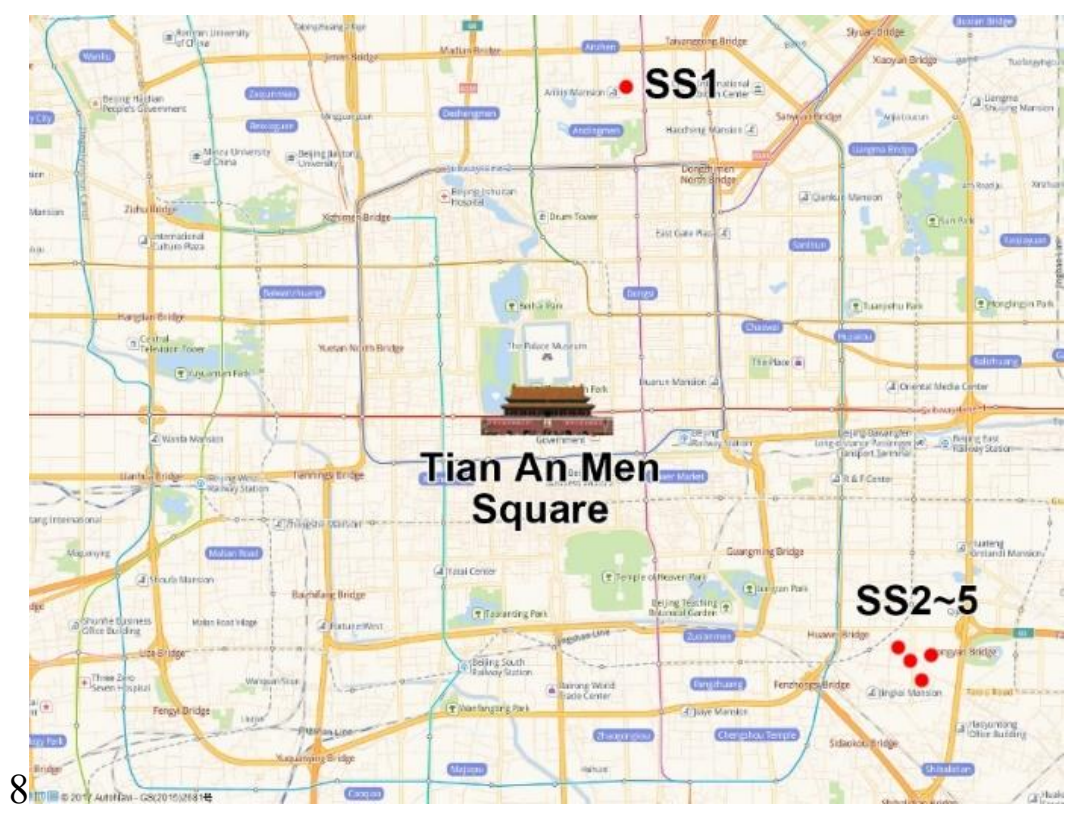


Figure 1: Locations of SS1 to SS5 in Beijing (scale of the map in 1:4000)

Table 1: Details of the five sampling sites

\begin{tabular}{ccccc}
\hline $\begin{array}{c}\text { Sampling } \\
\text { site }\end{array}$ & $\begin{array}{c}\text { Room size } \\
(H \times L \times W, \mathrm{~m})\end{array}$ & $\begin{array}{c}\text { Window } \\
\text { Types }\end{array}$ & $\begin{array}{c}\text { Window } \\
\text { Airtightness }^{*}\end{array}$ & $\begin{array}{c}\text { Openable area } \\
(H \times W, \mathrm{~m})\end{array}$ \\
\hline 1 & $3.0 \times 6.0 \times 4.0$ & Casement & 8 & $1.20 \times 0.90$ \\
2 & $3.3 \times 6.0 \times 3.0$ & Top-hung & 6 & $1.70 \times 0.90$ \\
3 & $2.9 \times 6.7 \times 4.1$ & Casement & 5 & $1.30 \times 0.60$ \\
4 & $3.0 \times 5.0 \times 4.8$ & Casement & 4 & $1.20 \times 0.80$ \\
5 & $3.7 \times 4.4 \times 5.9$ & Sliding & 3 & $1.07 \times 1.16$ \\
\hline
\end{tabular}

* These values were collected from the commissioning records of each case study room.

The Chinese standard, $G B / T$ 7106-2008, has given some reference values for windows with different airtightness levels, and Table 2 has listed some of them.

Table 2: Airtightness levels of external window in $G B / T$ 7106-2008

\begin{tabular}{c|cccccccc}
\hline Airtightness level & 1 & 2 & 3 & 4 & 5 & 6 & 7 & 8 \\
\hline$q$ & $3.5 \sim 4.0$ & $3.0 \sim 3.5$ & $2.5 \sim 3.0$ & $2.0 \sim 2.5$ & $1.5 \sim 2.0$ & $1.0 \sim 1.5$ & $0.5 \sim 1.0$ & $\leq 0.5$ \\
\hline
\end{tabular}

where, $q$ is the mean air infiltration rate on unit crack length, in $\mathrm{m}^{3} /(\mathrm{m} \cdot \mathrm{h})$, under the condition of $1 \mathrm{~atm}, 20^{\circ} \mathrm{C}$ and pressure difference between both sides of $10 \mathrm{~Pa}$.

In this study, each sampling site has only one external window and one interior door connected to the corridor, no inner windows. Throughout the monitoring period, all rooms were unoccupied, with no active natural and mechanical ventilation systems. It should be noted that in China external walls of buildings are commonly constructed by bricks or concrete, with thick thermal insulations outside. Therefore, infiltration generally not happens on external walls (Ji and Duanmu, 2017). Around external window, however, cracks may exist and these are common air leakage points in Chinese buildings. Additionally, all internal sources or sources from other rooms were well controlled by tapes to seal the cracks around interior doors, so indoor $\mathrm{PM}_{2.5}$ was mainly coming from infiltration around external windows.

During the study, both indoor and outdoor $\mathrm{PM}_{2.5}$ mass concentrations were concurrently measured and recorded by $\mathrm{LD}-5 \mathrm{C}(\mathrm{R})$ line particle monitors, embedded in an indoor air quality monitoring system. The device has a measurement range between 1 and $10000 \mu \mathrm{g} / \mathrm{m}^{3}$, with a resolution of $1 \mu \mathrm{g} / \mathrm{m}^{3}$ and error not exceeding $5 \%$ of measured 
values. Outdoor meteorological parameters, including temperature, relative humidity and wind speed, were recorded continuously and locally at each site, using FSR-4 meteorological systems. Data were recorded every 5 minutes automatically and uploaded to the server by a wireless network. The monitoring period was between $1^{\text {st }}$ March 2018 and $28^{\text {th }}$ February 2019, covering all four seasons of Beijing (Spring: between $1^{\text {st }}$ March and $31^{\text {st }}$ May; Summer: between $1^{\text {st }}$ June and $31^{\text {st }}$ August; Autumn: between $1^{\text {st }}$ September and $30^{\text {th }}$ November; Winter: between $1^{\text {st }}$ December and $28^{\text {th }}$ February in next year). A detailed description about the monitoring method is available in a previous published article by the authors (Chen et al., 2016). Before the measurement, all monitoring instruments were calibrated by their manufacturers to ensure accuracy.

\subsubsection{Monitored results of outdoor PM 2.5 mass concentration}

Figure 2 has depicted the monitored $\mathrm{PM}_{2.5}$ concentration from outdoors, using the average values collected from the two sites. During the monitoring period, the peak hourly average $\mathrm{PM}_{2.5}$ mass concentration was $520.5 \mu \mathrm{g} / \mathrm{m}^{3}$, with a yearly average value of $59.9 \mu \mathrm{g} / \mathrm{m}^{3}$. According to a classification method (Table 3) from the Chinese standard, Ambient air quality standards (GB 3095-2012), all monitored dates were classified into a pollution level and it shows the percentage of different dates in the whole year and in different seasons depicted in Figure 3. Figure 3 reveals that winter has highest pollution levels among all four seasons, with a mean $\mathrm{PM}_{2.5}$ mass concentration of $80.5 \mu \mathrm{g} / \mathrm{m}^{3}$, which was about 1.34 times higher than the yearly average value.

Table 3: Classification of atmospheric $\mathrm{PM}_{2.5}$ pollution levels in $G B$ 3095-2012

\begin{tabular}{cc}
\hline $\mathrm{PM}_{2.5}$ pollution level & Hourly standard $\left(\mu \mathrm{g} / \mathrm{m}^{3}\right)$ \\
\hline Excellent & $0 \sim 35$ \\
Acceptable & $35 \sim 75$ \\
Slightly polluted & $75 \sim 115$ \\
Moderately polluted & $115 \sim 150$ \\
Severely polluted & $150 \sim 250$ \\
Hazardous & $>250$ \\
\hline
\end{tabular}




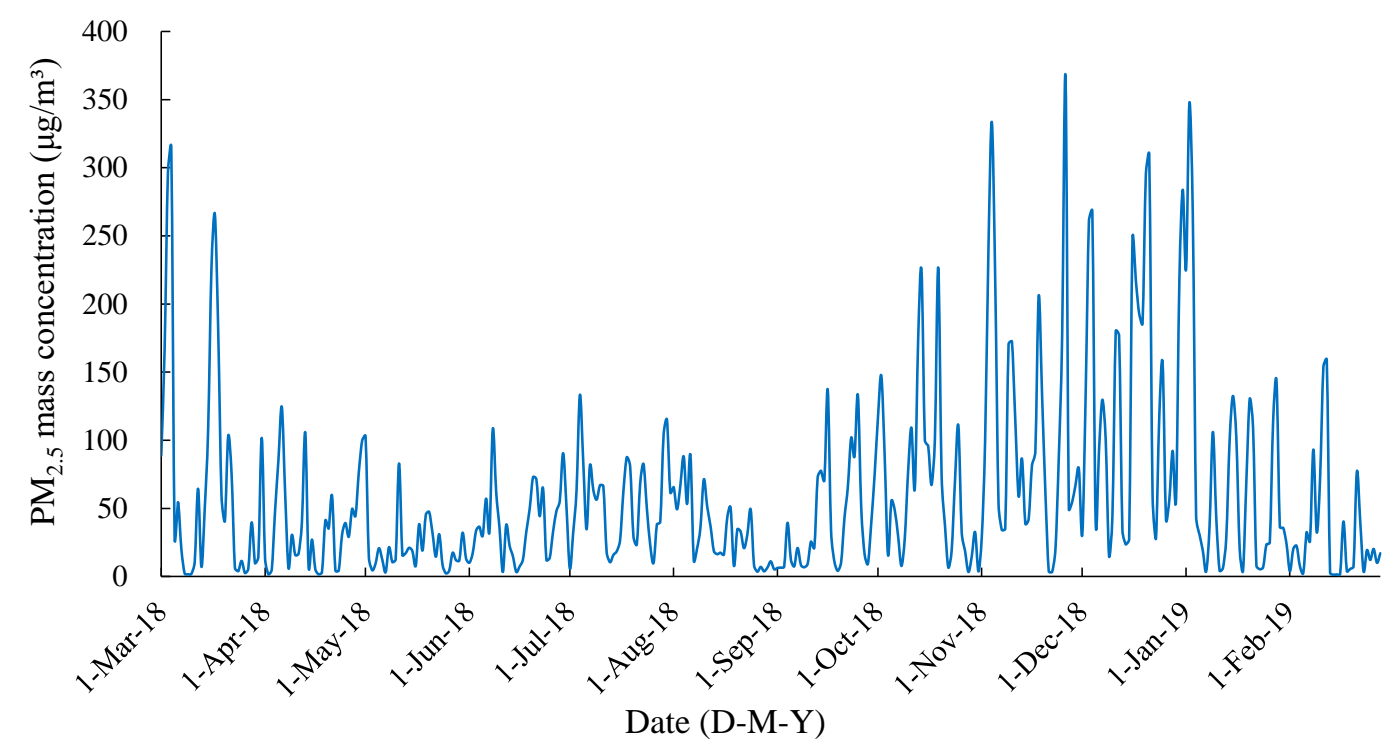

Figure 2: Outdoor $\mathbf{P M}_{2.5}$ mass concentrations during monitoring period (daily mean value)

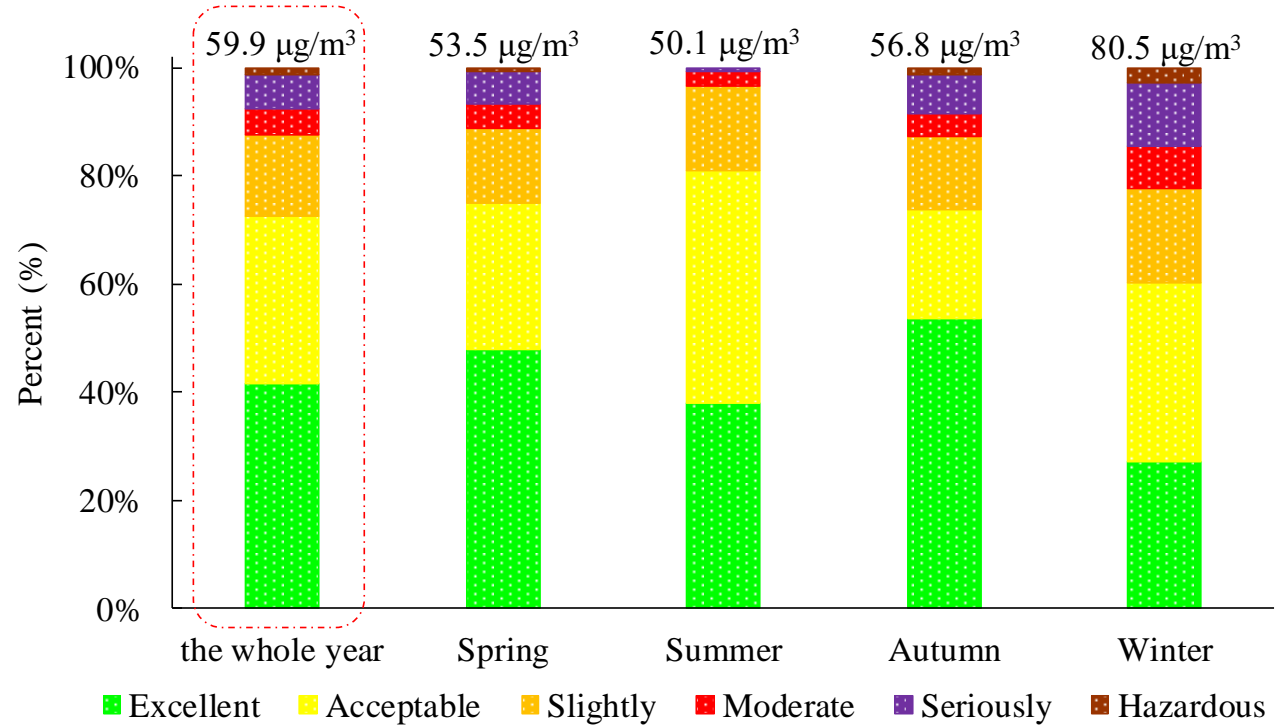

Figure 3: Distribution of outdoor $\mathbf{P M}_{2.5}$ mass concentrations classified into pollution levels

\subsubsection{Monitoring results of indoor PM2.5 pollution}

According to the results shown in Section 3.1.2, data from winter were used in the remaining part of this study, as it has the worst outdoor air quality when people use air cleaners most. Figure 4 reveals the frequency distribution of indoor $\mathrm{PM}_{2.5}$ pollution levels of all the five sampling sites in winter. Among them, the lowest average indoor $\mathrm{PM}_{2.5}$ mass concentration was $33.8 \mu \mathrm{g} / \mathrm{m}^{3}$ in SS1 (with external window airtightness in level-8), and the air quality standard rate was up to $91 \%$. However, indoor $\mathrm{PM}_{2.5}$ pollution levels performed an obvious upward trend when decreasing airtightness levels 
of windows. As for SS5 with window airtightness in level-3, the mean indoor $\mathrm{PM}_{2.5}$ mass concentration was $58.3 \mu \mathrm{g} / \mathrm{m}^{3}$, and the air quality standard rate was only $72 \%$.

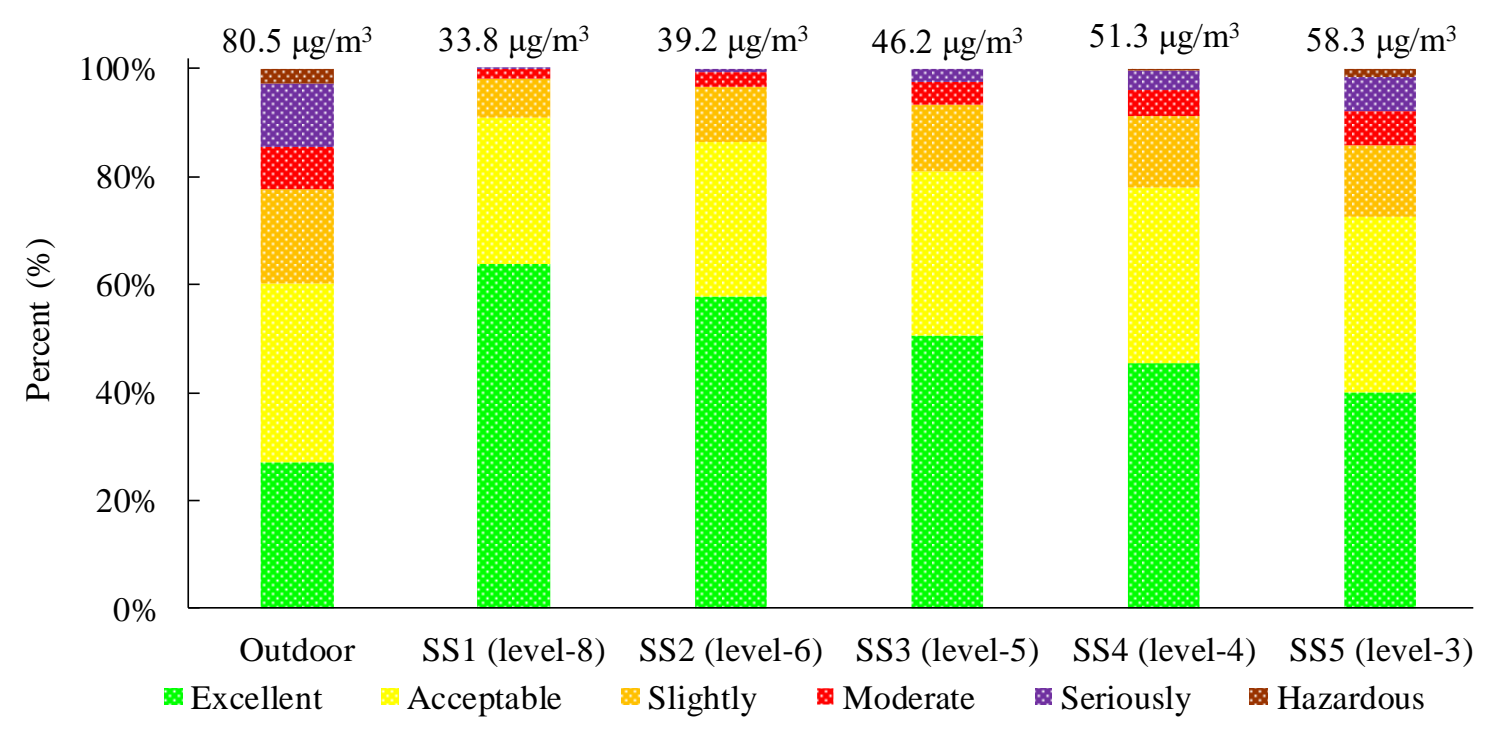

Figure 4: Distribution of indoor $\mathbf{P M}_{2.5}$ mass concentrations classified into pollution levels

\subsection{Model validation}

Using the data measured in Section 3.1, SS2 was used as an example to show how $a, P$ and $k$ were calculated. Table 4 has listed the measured indoor and outdoor $\mathrm{PM}_{2.5}$ mass concentrations for SS2 in six consecutive hours (i.e. between 9:00 and 14:00, $10^{\text {th }}$ Dec, 2018). Using Equations 3 and 4 , all 840 groups of $\left[a_{m, j}^{1}, a_{m, j}^{2}, \ldots, a_{m, j}^{5}\right]$ with their corresponding $\left[P_{m}, k_{j}\right]$ were calculated. Eliminating unreasonable groups of $a(a>1$ or $a<0$ ), the standard deviation $\delta_{m, j}$ of all valid $a$ groups was calculated by Equation 5, and Figure 5 has depicted the relationship between $\delta_{m, j}$ and $\left[P_{m}, k_{j}\right]$. It indicates that $\delta_{m, j}$ was mainly ranging between 0.08 and 3.69, and there was a strong correlation between $\delta_{m, j}$ and $\left[P_{m}, k_{j}\right]$.

Taking all sets with $5 \%$ lowest $\delta_{m, j}$, the hourly mean values of corresponding $\left[\overline{a_{m, j}^{1}}, \overline{a_{m, j}^{2}}, \ldots, \overline{a_{m, j}^{5}}\right]$ and mean $\left[\overline{P_{m}}, \overline{k_{j}}\right]$ were considered as reasonable solutions according to Bennett and Koutrakis (2006); Mleczkowska et al. (2016), with results of $\left[\overline{a_{m, j}^{1}}, \overline{a_{m, j}^{2}}, \ldots, \overline{a_{m, j}^{5}}\right]=\left[0.210,0.198,0.192,0.216,0.220\right.$, in $\left.^{-1}\right]$ (with a mean value of $\left.0.207 \mathrm{~h}^{-1}\right)$. Meanwhile, the mean penetration factor was $0.902 \pm 0.009$ and the mean deposition rate was $0.194 \pm 0.011 \mathrm{~h}^{-1}$, respectively. 
Table 4: Six consecutive hours indoor and outdoor $\mathbf{P M}_{2.5}$ mass concentrations

\begin{tabular}{ccccccc}
\hline & $9: 00$ & $10: 00$ & $11: 00$ & $12: 00$ & $13: 00$ & $14: 00$ \\
\hline$C_{\text {out }}\left(\mu \mathrm{g} / \mathrm{m}^{3}\right)$ & 134 & 126 & 130 & 151 & 188 & 209 \\
$C_{\text {in }}\left(\mu \mathrm{g} / \mathrm{m}^{3}\right)$ & 65 & 64 & 61 & 62 & 69 & 77 \\
\hline
\end{tabular}

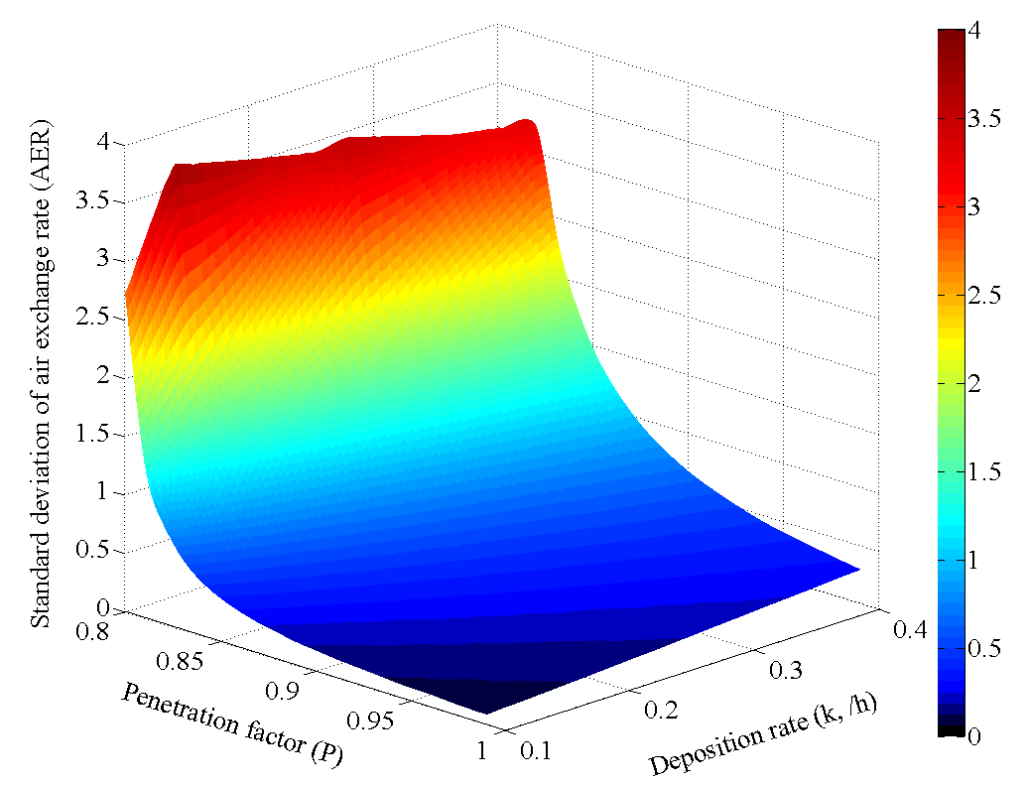

Figure 5: Standard deviation $\delta_{m, j}$ of $a$ corresponding to each group of $\left[P_{m}, k_{j}\right]$

Using the same method, other 50 groups of measured indoor and outdoor $\mathrm{PM}_{2.5}$ mass concentrations at SS2 in different months were selected to validate the calculated $P$ and $k$, with calculated results shown in Figure 6. The comparison shows good consistencies around the whole year in different seasons for both $P$ and $k$ and all values fell into reasonable ranges proposed by Bennett and Koutrakis (2006); Chen et al. (2012); Mleczkowska et al. (2016); Tian et al. (2009), indicating that the calculated $P$ and $k$ are reliable (both $P$ and $k$ should be independent of ambient climate conditions). Finally, the average values of all 51 calculations were adopted as the final value. 


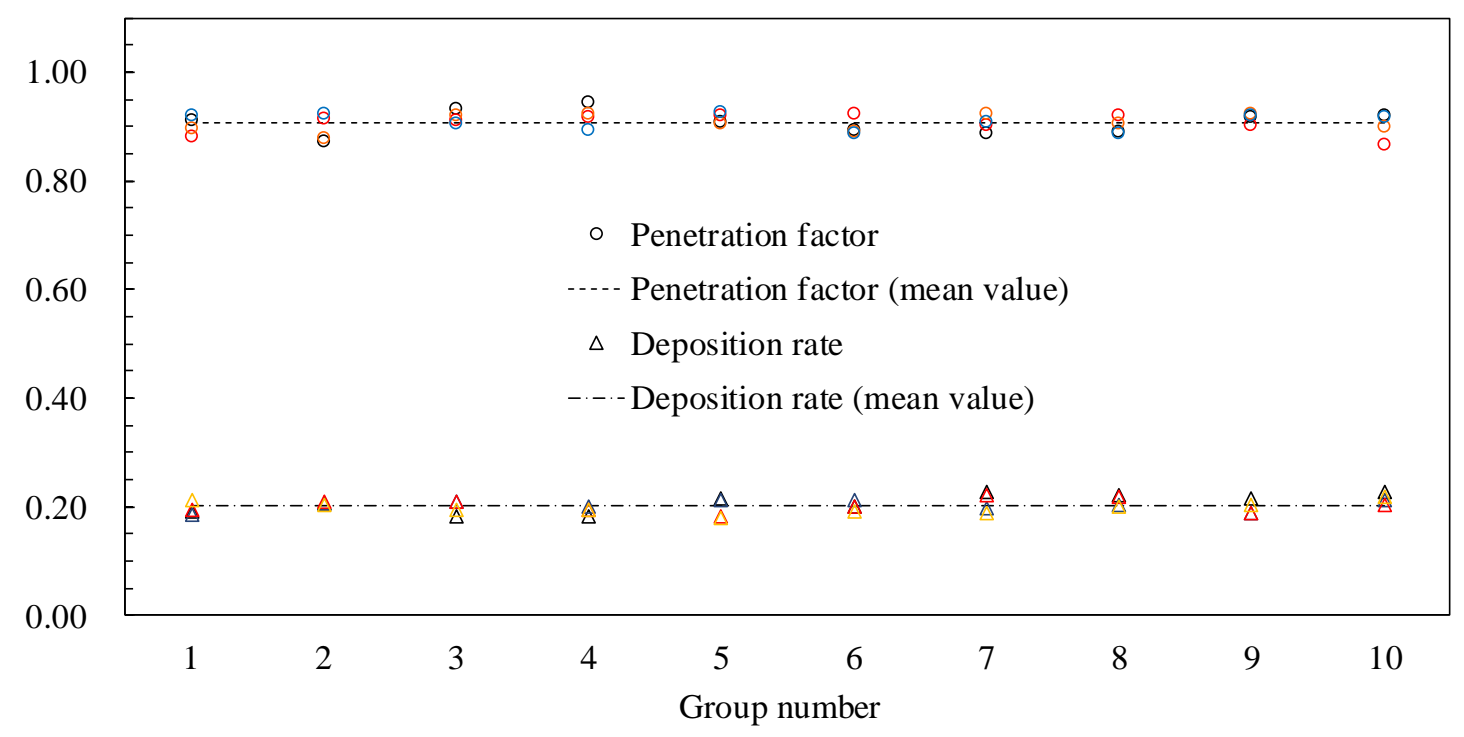

Figure 6: Calculation results of other 50 groups of $P$ and $k\left(\right.$ in $\left.^{-1}\right)$ under different seasons

(black means the data from spring, red from summer, yellow from autumn, blue from winter)

Repeating the method used in this section for SS2, the $P$ and $k$ for other sampling sites were also decided, as listed in Table 5. Comparing to two reasonable ranges of $P$ and $k$ which are proposed by Ji and Zhao (2015) through statistical analysis on large samples, the calculated $P$ and $k$ in this study are both within these ranges, enhancing confidence. Apparently, the calculated values listed in Table 5 indicate that better airtightness level of external windows gives lower $P$, with SS1 has the lowest $P(0.868)$ and SS5 has the highest $P(0.986)$, all higher than the recommended value in the standard, i.e. 0.800. For $k$, all calculated values were within the range of $0.194 \sim 0.205 \mathrm{~h}^{-}$ ${ }^{1}$ at all tested cases, and they were all close to the recommended value in the standard, i.e. $0.200 \mathrm{~h}^{-1}$, therefore, it seems to be reasonable to use $0.2 \mathrm{~h}^{-1}$ when selecting air cleaners.

Table 5: Determined $P$ and $\boldsymbol{k}$ values for different external window airtightness levels

\begin{tabular}{cccccc}
\hline $\begin{array}{c}\text { Sampling site } \\
\text { (window airtightness level) }\end{array}$ & $\begin{array}{c}\text { SS1 } \\
(\text { level-8) }\end{array}$ & $\begin{array}{c}\text { SS2 } \\
(\text { level-6) }\end{array}$ & $\begin{array}{c}\text { SS3 } \\
(\text { level-5) }\end{array}$ & $\begin{array}{c}\text { SS4 } \\
\text { (level-4) }\end{array}$ & $\begin{array}{c}\text { SS5 } \\
\text { (level-3) }\end{array}$ \\
\hline$P$ & 0.868 & 0.906 & 0.927 & 0.950 & 0.986 \\
\hline$k\left(\mathrm{~h}^{-1}\right)$ & 0.194 & 0.196 & 0.205 & 0.199 & 0.195 \\
\hline
\end{tabular}

For the air exchange rate, the validation of $a$ was done by the tracer gas decay method, which is a widely used in engineering applications (Carrilho et al., 2015; Cui 
et al., 2015; Kiwan et al., 2013; Montoya et al., 2011; Younes et al., 2012). The measurement of $\mathrm{CO}_{2}$ was done by the Lutron MCH-383SD, with a monitoring range of between 0 and 4000ppm and a measurement accuracy of $\pm 5 \%$ of reading. Also using SS2 as an example, Figure 7 has depicted both monitored outdoor and indoor $\mathrm{CO}_{2}$ concentrations, using the same time listed in Table 4. According to this method, $a$ was determined as $0.210 \mathrm{~h}^{-1}$, showing a good agreement with the calculated value in Section 3.2.1, i.e. $0.207 \mathrm{~h}^{-1}$, with a relative error of $1.4 \%$. In addition to this, the same method was repeated three times to ensure the conclusion, with satisfying results shown in Table 6.

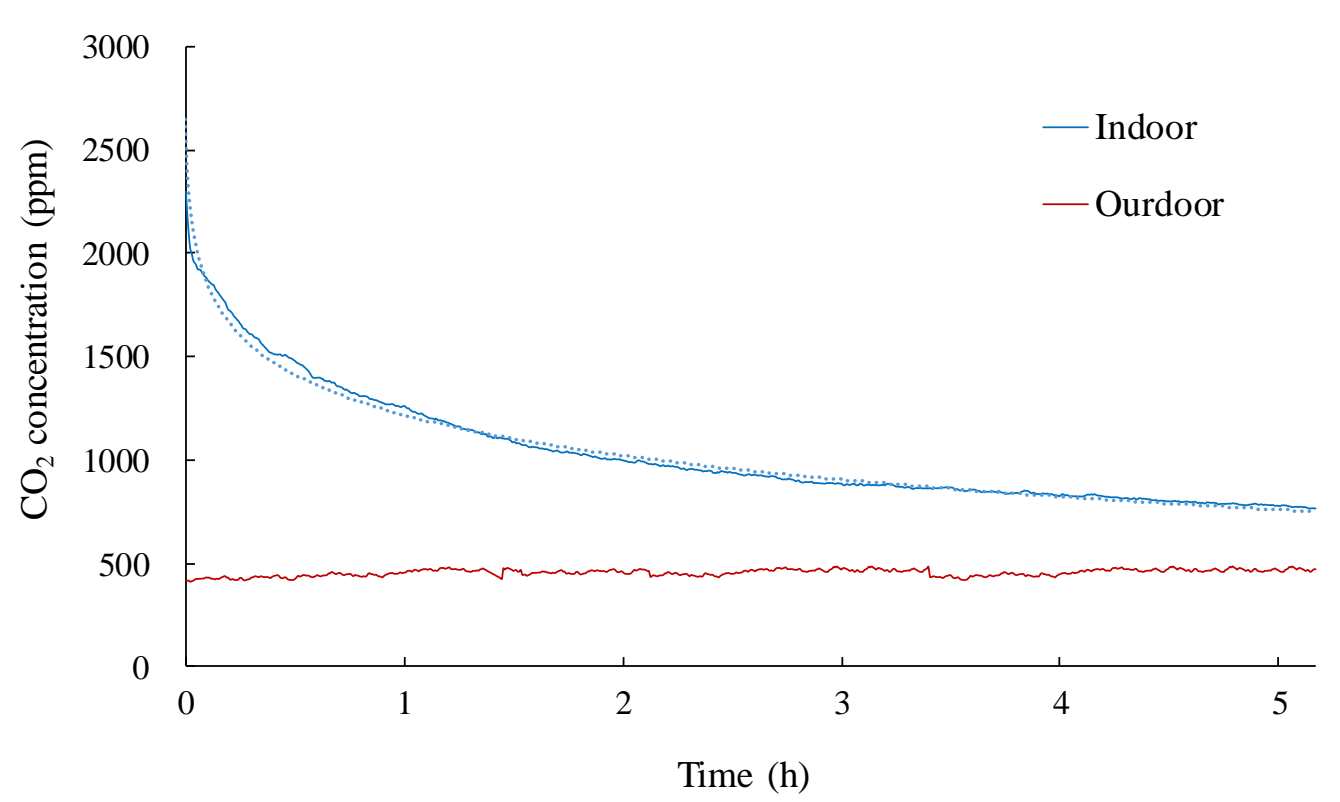

Figure 7: Monitored curve of both outdoor and indoor $\mathrm{CO}_{2}$ concentrations

Table 6: Comparison results of both measured and calculated air exchange rate

\begin{tabular}{cccc}
\hline Testing date & Measured $a\left(\mathrm{~h}^{-1}\right)$ & Calculated $a\left(\mathrm{~h}^{-1}\right)$ & Relative error (\%) \\
\hline $6^{\text {th }}$ Jul, 2018 & 0.252 & $0.248 \pm 0.015$ & $1.6 \%$ \\
$21^{\text {st }}$ Oct, 2018 & 0.212 & $0.217 \pm 0.016$ & $2.4 \%$ \\
$5^{\text {th }}$ Feb, 2019 & 0.231 & $0.236 \pm 0.012$ & $2.2 \%$ \\
\hline
\end{tabular}

According to discussions in Section 2.2, the stochastic nature of indoor-outdoor $\mathrm{PM}_{2.5}$ mass concentrations, as well as outdoor weather conditions, may bring uncertainties to the performance of the developed model here. The calculation results from this study, however, have shown that all $P, k$ and $a$ were not significantly affected by these uncertainties: 1$)$ both $P$ and $k$ were nearly constant for the same building with certain window airtightness level and room structure, as shown in Figure 5, and similar 
results have been shown in Chen et al. (2012); Tian et al. (2009); 2) the calculated values for $a$ were all within a reasonable range, i.e. 0 to $1 \mathrm{~h}^{-1}$, confirmed by Montoya et al. (2011); Shi et al. (2015); Yamamoto et al. (2010).

\section{Discussions}

Section 3 has justified the reliability of the model proposed in this study and in this section some further discussions were given. Section 4.1 has proposed a new parameter that can reflect external window infiltration properties independent on the length of cracks around windows, which is much possibly exist in real application due to different window sizes and structures. Section 4.2 has discussed the relationship between air cleaner effective area and CADR for different external window airtightness levels based on the calculation results of the three parameters.

\subsection{Air exchange rate by infiltration per unit window crack length $\left(q_{l}\right)$}

In this study, $a$ is a major parameter that should be calculated to guide selection of air cleaners. In real applications, however, windows may have different sizes and structures, and these differences will bring cracks with various lengths. This difference was also existing in this study, as all five windows investigated have different properties, as listed in Table 1. Therefore, the different $a$ calculated for the five sampling sites may not only because of their different airtightness levels, but also their different length of cracks. Therefore, to better reflect the impact from airtightness level, which is the target topic of this study, a new parameter was proposed, which was called air exchange rate by infiltration per unit window crack length, $\left(q_{l}\right.$, in $\left.\mathrm{m}^{3} /(\mathrm{m} \cdot \mathrm{h})\right)$, defined by Equation 6 ,

$$
q_{l}=\frac{a V}{l_{w}}
$$

where $V$ is room volume, (in $\left.\mathrm{m}^{3}\right) ; l_{w}$ is total length of window cracks, (in $\mathrm{m}$ ).

Figure 8 has depicted the calculated hourly $q_{l}$ for all SS1 to SS5, with its mean value ("ø" in the box diagram), higher and lower quartile values, as well as top and bottom $1 \%$ values. It could be obviously observed that a window with a higher airtightness level had a lower $q_{l}$ and it shown a more stable trend. 


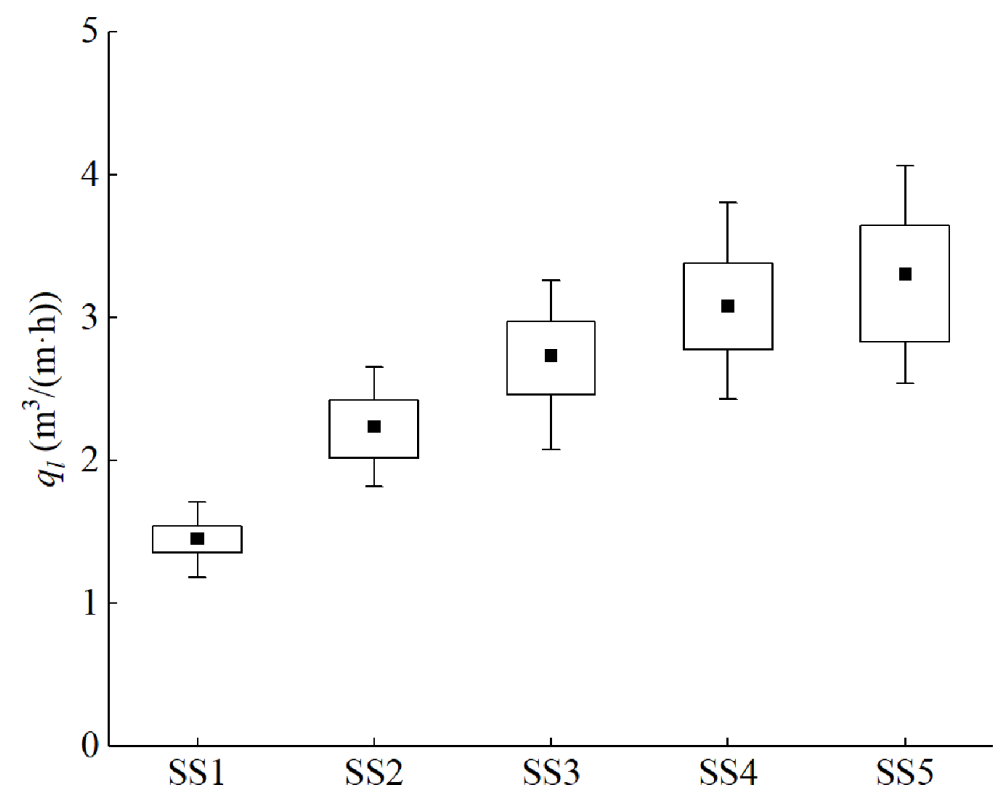

Figure 8: Calculated results of $q_{l}$ of each sampling site during winter

Apparently, the calculated values in Figure 8 for each window were varying around its mean value, with the minimum standard variation happened for SS1 (0.155) and the maximum standard variation happened for SS5 (0.424). When selecting air cleaners, however, a representative design value is needed. In this study, this value was determined according to the trend characteristics of $q_{l}$ cumulative frequency curves for all windows, and Figure 9 has depicted the results for all sampling sites. From Figure 9 , it could be observed that for all windows, at the start of the diagram the frequency increase was very small, until it reached about 5\%. On the other side, when the cumulative frequency was higher than $95 \%$ percent, the change was very stable as well. Between $5 \%$ and $95 \%$, the impact of increasing $q_{l}$ intervals seemed to be much more significant on the increase of cumulative frequency. Therefore, it seems to be reasonable of using $95 \%$ as a threshold to decide the recommended value of $q_{l}$. Table 7 has summarized the determined values of $q_{l}$ for all sampling sites. 

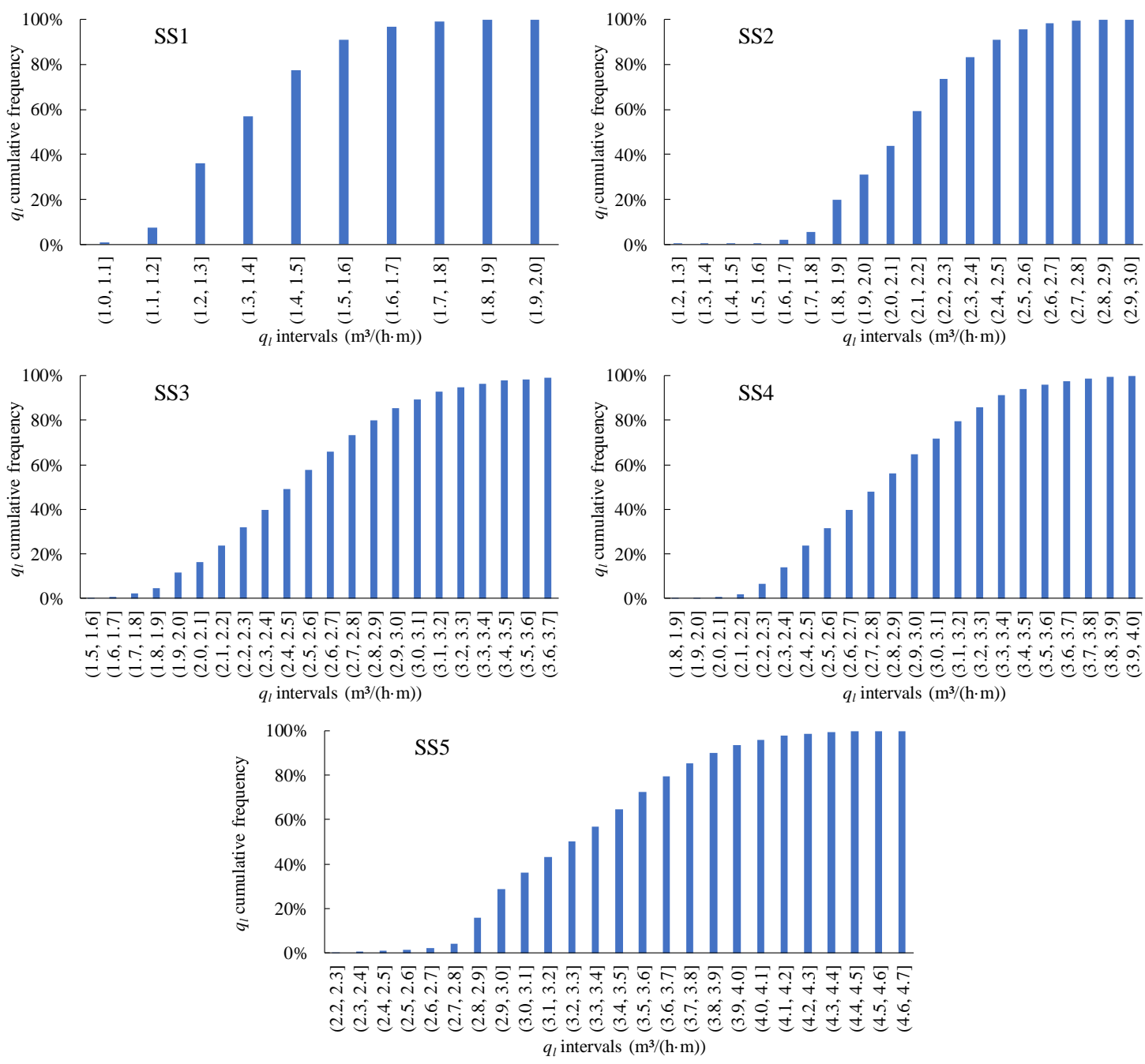

Figure 9: Distribution frequency of $q_{l}$ of SS5

Table 7: Determined values of $\boldsymbol{q}_{l}$ under different airtightness levels of windows

\begin{tabular}{cccccc}
\hline $\begin{array}{c}\text { Sampling site } \\
\text { (window airtightness level) }\end{array}$ & $\begin{array}{c}\text { SS1 } \\
(\text { level-8) }\end{array}$ & $\begin{array}{c}\text { SS2 } \\
(\text { level-6) }\end{array}$ & $\begin{array}{c}\text { SS3 } \\
(\text { level-5) }\end{array}$ & $\begin{array}{c}\text { SS4 } \\
(\text { level-4) }\end{array}$ & $\begin{array}{c}\text { SS5 } \\
(\text { level-3) }\end{array}$ \\
\hline$q_{l}\left(\mathrm{~m}^{3} /(\mathrm{h} \cdot \mathrm{m})\right)$ & 1.65 & 2.55 & 3.25 & 3.55 & 4.05 \\
\hline
\end{tabular}

\subsection{Selecting air cleaners according to window airtightness level}

In the Chinese standard $G B / T$ 18801-2015, a relationship between air cleaner effective area $(S)$ and CADR has been given, as defined by Equation 7 ,

$$
S \leq \frac{C_{\text {in }}}{\left[a P C_{\text {out }}-(a+k) C_{\text {in }}\right] H} \cdot Q_{C A D R}
$$

where $S$ is air cleaner effective area, in $\mathrm{m}^{2} ; H$ is room height, in $\mathrm{m}(H=2.4 \mathrm{~m}$ 
recommended in the standard); $\widetilde{C_{\text {out }}}$ and $\widetilde{C_{\text {in }}}$ are design outdoor $\mathrm{PM}_{2.5}$ mass concentration and target indoor $\mathrm{PM}_{2.5}$ mass concentration, respectively, both in $\mu \mathrm{g} / \mathrm{m}^{3}$ (in the standard, they were $300 \mu \mathrm{g} / \mathrm{m}^{3}$ and $35 \mu \mathrm{g} / \mathrm{m}^{3}$ ).

According to Equation 7, $\frac{C_{\text {in }}}{\left[a P C_{\text {out }}-(a+k) C_{i n}\right] H}$ can be used to define the relationship between $S$ and CADR. Using the values listed in Table 5 and Table 7. $\frac{C_{\text {in }}}{\left[a P C_{\text {out }}-(a+k) C_{\text {in }}\right] H}$ could be decided for using $a, P$ and $k$ for external windows with different airtightness levels, and the results have been listed in Table 8. The calculation results indicated that with increased window airtightness level, the required CADR of air cleaners showed a downward trend, which means an air cleaner with smaller size, lower energy consumption and less material. For example, to achieve the same purification effect, the required CADR for SS1 is only $30 \%$ of that value for SS5.

Table 8: Relationship between air cleaner effective area and CADR for different window airtightness levels

\begin{tabular}{cccccc}
\hline $\begin{array}{c}\text { Sampling site } \\
\text { (window airtightness level) }\end{array}$ & $\begin{array}{c}\text { SS1 } \\
(\text { level-8) }\end{array}$ & $\begin{array}{c}\text { SS2 } \\
(\text { level-6) }\end{array}$ & $\begin{array}{c}\text { SS3 } \\
(\text { level-5) }\end{array}$ & $\begin{array}{c}\text { SS4 } \\
(\text { level-4) }\end{array}$ & $\begin{array}{c}\text { SS5 } \\
\text { (level-3) }\end{array}$ \\
\hline$\frac{C_{\text {in }}}{\left[a P C_{\text {out }}-(a+k) C_{\text {in }}\right] H}(\mathrm{~h} / \mathrm{m})$ & 0.38 & 0.25 & 0.20 & 0.15 & 0.11 \\
\hline
\end{tabular}

\section{Conclusions}

To obtain a healthy indoor air quality, air cleaners are popularly used in residential application in China to deal with serious atmosphere $\mathrm{PM}_{2.5}$ pollution issue. An accurate selection of air cleaners will help to better control indoor $\mathrm{PM}_{2.5}$ mass concentration, as well as reducing unnecessary cost. When selecting air cleaners, three factors, namely, Air exchange rate $(a)$, particle penetration factor $(P)$ and deposition rate $(k)$, are key. In current national standard, however, constant values were recommended for them, ignoring the impact from various window airtightness levels. This study, therefore, tried to justify the significance of this impact and proposed a relationship between window airtightness level and selection of air cleaners. Key findings from this study include:

1) A calculation method for deciding $q_{l}, P$ and $k$, based on monitored indoor and outdoor $\mathrm{PM}_{2.5}$ mass concentrations has been developed, and the recommended values of the three parameters under different external window airtightness 
levels were proposed;

2) Both $q_{l}$ and $P$ were significantly influenced by the airtightness level of windows, with high window airtightness level having low values for $q_{l}$ and $P$. Additionally, both their values were found to be different from the recommended values in the current Chinese standard, which providing evidence to support future standard revision and update.

3) Calculated $k$ showed good agreement with the recommended value in the current Chinese standard, i.e. $0.2 \mathrm{~h}^{-1}$. Therefore, it seems to be reasonable to use $0.2 \mathrm{~h}^{-1}$ when selecting air cleaners;

4) With increased window airtightness level, the required CADR of air cleaners showed a downward trend, which means an air cleaner with smaller size, lower energy consumption and less material.

Future work from this study would include:

1) Considering the dynamically changing outdoor $\mathrm{PM}_{2.5}$ mass concentration on the selection method developed here;

2) Identifying the relationship between air cleaner rated air flow and $\mathrm{PM}_{2.5}$ weight filtration efficiency of mounted air filters.

\section{Acknowledgement}

The authors would like to acknowledge the coordinated support from Natural Science Foundation of China (Grant No. 51778593), the $13^{\text {th }}$ Five-Year Key Project, Ministry of Science and Technology of China (Grant No. 2017YFC0702800) and Youth Scientific Research Fund of China Academy of Building Research (Grant Recipients: Zijia Liu and Ziguang Chen).

\section{References}

Bennett, D.H., Koutrakis, P., 2006. Determining the infiltration of outdoor particles in the indoor environment using a dynamic model. J Aerosol Sci 37, 766-785.

Carrilho, J.D., Mateus, M., Batterman, S., da Silva, M.G., 2015. Air exchange rates from atmospheric CO2 daily cycle. Energy and Buildings 92, 188-194.

Chan, C.K., Yao, X., 2008. Air pollution in mega cities in China. Atmospheric Environment 42, 1-42.

Chatzidiakou, L., Mumovic, D., Summerfield, A.J., 2012. What do we know about indoor air quality in school classrooms? A critical review of the literature. Intelligent Buildings International 4, 228 259. 
Chen, C., Zhao, B., 2011. Review of relationship between indoor and outdoor particles: I/O ratio, infiltration factor and penetration factor. Atmospheric Environment 45, 275-288.

Chen, C., Zhao, B., Zhou, W.T., Jiang, X.Y., Tan, Z.C., 2012. A methodology for predicting particle penetration factor through cracks of windows and doors for actual engineering application. Build Environ 47, 339-348.

Chen, Z., Chen, C., Wei, S., Wu, Y., Wang, Y., Wan, Y., 2016. Impact of the external window crack structure on indoor PM2.5 mass concentration. Build Environ 108, 240-251.

Cui, S.Q., Cohen, M., Stabat, P., Marchio, D., 2015. CO2 tracer gas concentration decay method for measuring air change rate. Build Environ 84, 162-169.

Deng, G., Li, Z., Wang, Z., Gao, J., Xu, Z., Li, J., Wang, Z., 2017. Indoor/outdoor relationship of PM2.5 concentration in typical buildings with and without air cleaning in Beijing. Indoor and Built Environment 26, 60-68.

Deng, Y., Zhuangbo, F., Fang, J., Cao, S.-J., 2018. Impact of Ventilation Rates on Indoor Thermal Comfort and Energy Efficiency of Ground-Source Heat Pump System. Sustainable Cities and Society $37,154-163$.

El Hamdani, S., Limam, K., Abadie, M.O., Bendou, A., 2008. Deposition of fine particles on building internal surfaces. Atmospheric Environment 42, 8893-8901.

Fang, B., Zhang, L., Zeng, H., Liu, J., Yang, Z., Wang, H., Wang, Q., Wang, M., 2020. PM2.5-Bound Polycyclic Aromatic Hydrocarbons: Sources and Health Risk during Non-Heating and Heating Periods (Tangshan, China). International journal of environmental research and public health 17.

Ji, W., Zhao, B., 2015. Contribution of outdoor-originating particles, indoor-emitted particles and indoor secondary organic aerosol (SOA) to residential indoor PM2.5 concentration: A model-based estimation. Build Environ 90, 196-205.

Ji, Y., Duanmu, L., 2017. Airtightness field tests of residential buildings in Dalian, China. Build Environ 119, 20-30.

Jin, X., Yang, L., Du, X., Yang, Y., 2016. Particle transport characteristics in indoor environment with an air cleaner. Indoor and Built Environment 25, 987-996.

Kiwan, A., Berg, W., Fiedler, M., Ammon, C., Glaser, M., Muller, H.J., Brunsch, R., 2013. Air exchange rate measurements in naturally ventilated dairy buildings using the tracer gas decay method with Kr-85, compared to $\mathrm{CO} 2$ mace balance and discharge coefficient methods. Biosyst Eng 116, 286-296.

Kong, L.W., Hu, M., Tan, Q.W., Feng, M., Qu, Y., An, J.L., Zhang, Y.H., Liu, X.G., Cheng, N.L., 2020. Aerosol optical properties under different pollution levels in the Pearl River Delta (PRD) region of China. J. Environ. Sci. 87, 49-59.

Lai, A., 2003. Particle deposition indoors: A review. Indoor air 12, 211-214.

Li, Y., Chen, Z., 2003. A balance-point method for assessing the effect of natural ventilation on indoor particle concentrations. Atmospheric Environment 37, 4277-4285.

Liu, G., Xiao, M., Zhang, X., Gal, C., Chen, X., Liu, L., Pan, S., Wu, J., Tang, L., Clements-Croome, D., 2017. A review of air filtration technologies for sustainable and healthy building ventilation. Sustainable Cities and Society 32, 375-396.

Liu, X., Liu, X., Zhang, T., Guan, B., 2019. On-site measurement of winter indoor environment and air infiltration in an airport terminal. Indoor and Built Environment 28, 564-578.

Martins, N.R., Carrilho da Graça, G., 2018. Impact of PM2.5 in indoor urban environments: A review. Sustainable Cities and Society 42, 259-275. 
Mleczkowska, A., Strojecki, M., Bratasz, L., Kozlowski, R., 2016. Particle penetration and deposition inside historical churches. Build Environ 95, 291-298.

Montoya, M.I., Pastor, E., Planas, E., 2011. Air infiltration in Catalan dwellings and sealed rooms: An experimental study. Fuel \& Energy Abstracts 46, 2003-2011.

Pateraki, S., Asimakopoulos, D.N., Maggos, T., Assimakopoulos, V.D., Bougiatioti, A., Bairachtari, K., Vasilakos, C., Mihalopoulos, N., 2020. Chemical characterization, sources and potential health risk of PM2.5 and PM1 pollution across the Greater Athens Area. Chemosphere 241, 125026.

Provan, T.F., Younger, J.D., 1986. Air infiltration characteristics of windows. Energy and Buildings 9, 281-292.

Roelofsen, P., 2018. A new methodology for the evaluation of the perceived air quality depending on the air pollution, caused by human bioeffluents, the temperature, the humidity as well as the air velocity. Intelligent Buildings International 10, 154-161.

Salonen, H., Lahtinen, M., Lappalainen, S., Nevala, N., Knibbs, L.D., Morawska, L., Reijula, K., 2013. Physical characteristics of the indoor environment that affect health and wellbeing in healthcare facilities: a review. Intelligent Buildings International 5, 3-25.

Sharmin, T., Gül, M., Li, X., Ganev, V., Nikolaidis, I., Al-Hussein, M., 2014. Monitoring building energy consumption, thermal performance, and indoor air quality in a cold climate region. Sustainable Cities and Society 13, 57-68.

Shaughnessy, R.J., Sextro, R.G., 2006. What Is an Effective Portable Air Cleaning Device? A Review. Journal of Occupational and Environmental Hygiene 3, 169-181.

Shi, S., Chen, C., Zhao, B., 2015. Air infiltration rate distributions of residences in Beijing. Build Environ 92, 528-537.

Stapleton, E., Ruiz-Rudolph, P., 2018. The potential for indoor ultrafine particle reduction using vegetation under laboratory conditions. Indoor and Built Environment 27, 70-83.

Tian, L.W., Zhang, G.Q., Lin, Y.L., Yu, J.H., Zhou, J., Zhang, Q., 2009. Mathematical model of particle penetration through smooth/rough building envelop leakages. Build Environ 44, 1144-1149.

Tran, D.T., Alleman, L.Y., Coddeville, P., Galloo, J.-C., 2017. Indoor particle dynamics in schools: Determination of air exchange rate, size-resolved particle deposition rate and penetration factor in real-life conditions. Indoor and Built Environment 26, 1335-1350.

Velasco, E., Rastan, S., 2015. Air quality in Singapore during the 2013 smoke-haze episode over the Strait of Malacca: Lessons learned. Sustainable Cities and Society 17, 122-131.

Wallace, L., 1996. Indoor Particles: A Review. Journal of the Air \& Waste Management Association 46, 98-126.

Xu, Z., 2019. Air Purifier: Property, Assessment and Applications. Singapore, Beijing.

Yamamoto, N., Shendell, D.G., Winer, A.M., Zhang, J., 2010. Residential air exchange rates in three major US metropolitan areas: results from the Relationship Among Indoor, Outdoor, and Personal Air Study 1999-2001. Indoor Air 20, 85-90.

Younes, C., Abishdid, C., Bitsuamlak, G., 2012. Air infiltration through building envelopes: A review. Journal of Building Physics 35, 267-302.

Zhang, Y., Mo, J., Li, Y., Sundell, J., Wargocki, P., Zhang, J., Little, J.C., Corsi, R., Deng, Q., Leung, M.H.K., Fang, L., Chen, W., Li, J., Sun, Y., 2011. Can commonly-used fan-driven air cleaning technologies improve indoor air quality? A literature review. Atmospheric Environment 45, 4329-4343.

Zhao, B., Wu, J., 2007. Particle deposition in indoor environments: Analysis of influencing factors. 
Journal of Hazardous Materials 147, 439-448.

Zhao, X., Wang, S., Yin, X., Yu, J., Ding, B., 2016. Slip-Effect Functional Air Filter for Efficient Purification of PM2.5. Scientific Reports 6, 35472. 